obtained the definition was found to be very good, but on account of the difference in the lengths of the exposures given to the several plates, some of them proved to be rather thin. The task of developing them was imposed upon Prof. Charroppin, who gives a brief, interesting account of the process of their development. The observations of the times of contact and the study of the corona were undertaken by Prof. Engler, with the aid of the French instrument. Although only two contacts were recorded (the second and the fourth), he made no attempt at the third, owing to the short space of time at his disposal for observing and sketching the corona. The drawing which he made is produced (together with the other photographs) in this report, and tallies, when compared with them, in nearly all respects, with the exception of the two equatorial streamers on the west side, that appear to extend further westward than those recorded in the photographs.

It is interesting to note in the illustrations the great similarity between the corona observed in this eclipse and that of the year 1878 , in which year the sun-spot disturbances were at the minimum. Figs. 1 and 2 represent the corona of the year 1889 , the former being a drawing by Prof. Engler, the same as the one previously mentioned, while the latter is the integrated result of the examination of all the photographic plates, and "does not represent the corona as seen by the eye, nor as shown on any one of the negatives, but is a combination of all that could be found in the negatives."

The next illustration (Fig. 3 ) is a sketch of the corona made by Mr. Lockyer during the eclipse of 1878 (NATURE, vol. xviii. p. 457), and when compared with the above figures fully bears out the idea that at the several periods throughout a sunspot cycle there corresponds in the corona a like period, which is apparent to us only in the changes of form undergone by the equatorial and polar streamers, and this only at the time of eclipses.

The following brief extracts, which we give in the observers' own words, will show how the descriptions of the appearance of the corona resembled one another in all the main points. With regard to the structure at the north and south poles, Mr. Lockyer says (NATURE, vol. xviii. p. 457) :-

"I had a magnificent view of the corona with a power of 50 on my $3 \frac{3}{4}$-inch Cooke, and saw exquisite structure at the north and south points, Curves of contrary flexure started thence, and turned over, and blended with the rest of the corona, which was entirely structureless and cloudlike; the filamentous tracery, which in India I observed till three minutes after totality, had indeed almost gone. Prof. Bass, however, tells me that by confining his attention to the same point for nearly the whole time of totality, the structure came out and seemed to pulsate like an aurora."

Prof. Pritchett's account is almost the same, word for word, as may be seen from the following extract :-

"I was particularly struck," he says, "with the brilliant appearance in the telescope of the filaments at the north and south limbs of the sun. They seemed radial at the poles, but gradually bending over and merging into the equatorial streamers in passing from the pole to the equator. I could not resist the impression that these filaments pulsated.'

From the above it will be seen that the appearances at the pole for both years were very similar; and with regard to the equatorial streamers also, their notes show that the characteristic features of each coincided in almost all particulars. Owing to the fact of the minimum spot period occurring at both eclipses, the above results strengthen very considerably the hypothesis connecting the spot cycle with the corona.

In addition to Prof. Engler's drawing mentioned above, Señor Valle also made some eye observations of the coronal streamers. The method he adopted was similar to that employed by Prof. Newton in 1878, and consisted in placing a screen in such a position that during totality the moon and the brighter corona were cut off. The photo-engraving of the drawing shows an extension of the equatorial streamers to about a distance of three solar diameters, while the polar regions were described as of a curved luminous filamentary contraction.

Before concluding, we must not forget to mention the admirable artotype reproductions, at the end of the report, of all the negatives: as they are arranged in the order of the times of exposure, they show well the progressive increase of detail on the outer part of the corona as the exposure was lengthened.

\section{SIMPLE PROOF OF EUCLID II. 9 AND Io.}

THE following proof of Euclid II., 9 and Io, believed to be new, due to Miss Hilda Hudson, was communicated to the London Mathematical Society at their last meeting.

$\mathrm{AB}$ is bisected in $\mathrm{C}$ and divided unequally in $\mathrm{D}$ either internally (II. 9) or externally (II. IO). It is required to prove that the sum of the squares on $A D$ and $D B$ is equal to twice the sum of the squares on $A C$ and $C D$.

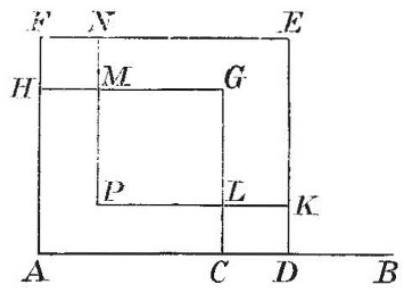

II.9.

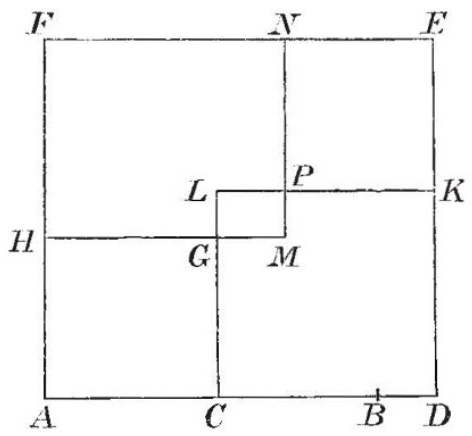

71.10 .

On $\mathrm{AD}, \mathrm{AC}, \mathrm{CD}$, describe the squares $\mathrm{ADEF}, \mathrm{ACGH}$, CDKL, all on the same side of $A B$.

On FH, within the square $\mathrm{AE}$, describe the square FHMN ; this is equal to the square on $\mathrm{CD}$.

Let NM, KL, produced if necessary, meet in $\mathrm{P}$.

Then $\mathrm{PE}$ is a square equal to the square on $\mathrm{AC}$.

And.PG is a square equal to the square on $\mathrm{DB}$.

The sum of the squares on $\mathrm{AD}, \mathrm{DB}$ is equal to the figures $\mathrm{AE}$ and $\mathrm{PG}$, that is to $\mathrm{AG}, \mathrm{PE}, \mathrm{FM}$, and $\mathrm{CK}$, that is to twice the sum of $\mathrm{AG}, \mathrm{CK}$, that is to twice the sum of the squares on $\mathrm{AC}$, CN.

\section{SCIENTIFIC SERIALS.}

American Meteorological Journal for November.-Prof. H. A. Hazen gives the results of three rather high balloon voyages in the United States, in which he took part. (I) June 25, 1886, at 7 h. $50 \mathrm{Om}$. a.m., a dense cloud was entered at Iooo feet, which seemed like a dry fog. The temperature from the earth up to more than half-way through the cloud hardly varied a degree, but after that it rose rapidly. There was a region of marked dampness at 7000 feet. The temperature at starting was $6 \mathrm{r}^{\circ} \cdot 3$, and at 9640 feet it had fallen to $8^{\circ}$; time, 9 h. $16 \mathrm{~m}$. (2) June II, 1887 , at $2 \mathrm{~h}$. $34 \mathrm{~m}$. p.m., temperature $90^{\circ} \cdot 6$. At 15,080 feet, it had fallen to $40^{\circ}$; time, $6 \mathrm{~h}$. $18 \mathrm{~m}$. p.m. Great dryness was experienced in the upper strata. There were two rather sharply defined layers of dampness, at 7500 feet and at 12,000 feet. (3) August 13,1887 , at $3 \mathrm{~h} .35 \mathrm{~m}$. p.m., temperature $75^{\circ} \cdot 8$. At 694 o feet it was $53^{\circ} \cdot 3$; time, $6 \mathrm{~h} .28 \mathrm{~m}$. p. m. The relative humidity fell to 8 per cent. - Meteorology at the French Association at Marseilles, by A. L. Rotch. Among the most interesting papers was one by M. Crova, upon the analysis of diffused light. Observations made at Montpellier at the zenith show the blue to be greatest in the early morning, and least about 2 p.m., and then increasing until towards evening. A cloudy sky also shows

NO. I I 56, vOL. 45] 
a considerable amount of blue rays. M. Teisserenc de Bort explained the existence of a vertical barometric gradient, first noticed in mountain observations, but lately measured more exactly on the Eiffel Tower. - The zodiacal light as related to terrestrial temperature observations, by $\mathrm{O}$. T. Sherman.Features of Hawaiian climate, by C. L. Lyons, in charge of the Weather Service there. The temperature averages for January are $69^{\circ}$ to $71^{\circ}$, and in July and August $78^{\circ}$ and $79^{\circ}$. The daily range is greater than is generally supposed, averaging $\mathbf{I} \mathbf{I}^{\circ}$ for the year, and some days over $20^{\circ}$. The maximum temperature is $89^{\circ}$, and the minimum $55^{\circ}$. - High-level meteorological observatories in France, by A. L. Rotch; and other articles of minor importance.

\section{SOCIETIES AND ACADEMIES. LONDON.}

Royal Society, December I7.-“" The 'Ginger-beer Plant, and the Organisms composing it : a Contribution to the Study of Fermentation-yeasts and Bacteria." By H. Marshall Ward, Sc.D., F.R.S., F.L.S., Professor of Botany at the Forest School, Royal Indian Engineering College, Cooper's Hill.

The author has been engaged for some time in the investigation of a remarkable compound organism known to villagers as the " ginger-beer plant."

It occurs as jelly-like, semi-transparent, yellowish-white masses, aggregated into brain-like clumps, or forming deposits at the bottom of the fermentations, and presents resemblances to the so-called Kephir grains of the Caucasus, with which, however, it is by no means identical.

He finds that it consists essentially of a symbiotic association of a specific Saccharomycete and a Schizomycete, but, as met with naturally, invariably has other species of yeasts, bacteria, and mould-fungi casually associated with these.

He has successfully undertaken the separation of the various forms, and groups then as follows :-

(I) The essential organisms are a yeast, which turns out to be a new species allied to Saccharomyces ellipsoideus (Reess and Hansen), and which he proposes to call $S$ pyriformis; and a bacterium, also new and of a new type, and named by him Bacterium vermiforme.

(2) Two other forms were met with in all the specimens (from various parts of the country and from America) examined - Mycoderma cerevisia (Desm.) and Bacterium aceti (Kützing and Zopf).

(3) As foreign intruders, more or less commonly occurring in the various specimens examined, were the following :-

a. A pink or rosy yeast-like form-Cryptococcus glutinis (Fresenius)?

$\beta$. A small white aërobian top-yeast, with peculiar characters, and not identified with any known form.

$\gamma$. The ordinary beer-yeast-Saccharomyces cerevisice (Meyen and Hansen).

$\delta$. Three, or probably four, unknown yeasts of rare occurrence.

є. A bacillus which forms spores, and liquefies gelatine with a greenish tinge.

$\zeta$. A large spore-forming bacillus, which also liquefies gelatine.

$\eta$ and $\theta$. Two--perhaps three-other Schizomycetes not identified.

t. A large yeast-like form which grows into a mycelium, and turns out to be Ö̈dium lactis (Fresenius).

к. A common blue mould-Penicillium glaucum (Link).

$\lambda$. A brown "Torula"-like form, which turns out to be Dematium pullulans (De Bary).

$\mu$. One, or perhaps several, species of "Torula" of unknown origin and fates.

Saccharomyces pyriformis (n. sp.) is a remarkably anaërobian bottom-yeast, forming spores, and developing large quantities of carbon dioxide, but forming little alcohol. It has also an aërobian form-veil form of Hansen-in which the rounded cells grow out into club-shaped or pyriform cells, whence the proposed specific name. It inverts cane sugar, and ferments the products ; but it is unable to ferment milk sugar. It forms rounded, morula-like, white colonies in gelatine, and the author has separated pure cultures from these. $\mathrm{He}$ has also studied the development and germination of the spores, which are formed in 24 to 48 hours at suitable temperatures on porous earthenware blocks. They also develop on gelatine.

$$
\text { No. I I } 56 \text {, voL. } 45]
$$

The specific Schizomycete (Bacterium vermiforme, n. sp.) has been very fnlly studied by the author. It occurs in the fermentations as rodlets or filaments, curved or straight, encased in a remarkably thick, firm, gelatinous sheath, and is pronouncedly anaërobic, so much so, that the best results are got by cultivating it in carbon dioxide under pressure.

The sheathed filaments are so like worms, that the name proposed for the species is appropriately derived from this character.

It will not grow on, gelatine, and separation cultures had to be made in saccharine Jiquids by the dilution methods.

It grows best in solutions of beet-root, or of cane sugar, with relatively large quantities of nitrogenous organic matter-e.g. bouillon, asparagin-and tartaric acid. Good results were obtained with mixtures of Pasteur's solution and bouillon.

The author found that the bacterium into which the filaments subsequently break up can escape from its sheath and become free, in which state it divides rapidly, like ordinary bacteria. Eventually, all the forms-filaments, long rods, short rodletsbreak up into cocci. No spores have been observed. These changes are dependent especially on the nutritive medium, but are also affected by the gaseous environment and the temperature. The jelly-like clumps of the so-called " ginger-beer plant" are essentially composed of these sheathed and coiled Schizomycetes, entangling the cells of Saciharomyces pyriformis. But the fermentative actions of the Schizomycete on the saccharine medium are different when alone, from those exercised when associated with the yeast, or from those exerted by the latter alone.

This was proved by cultivating each separately, and also by cultivations in which, while each organism was submerged in the same fermentable mediun, they were separated by permeable porcelain (Chamberland filters), through which neither could pass.

The author has also reconstructed the "ginger-beer plant" by mixing pure cultures of the above two organisms; the Schizomycete entangled the yeast-cells in its gelatinous coils, and the synthesized compound organism behaved as the specimens not analyzed into their constituents. The symbiotic compound organism so closely resembles a lichen, in its morphological aspects, that it may be said to be a ferment-lichen.

Some very curious phenomena in connection with the forma. tion of the gelatinous sheaths and the escape of the bacteria from them were observed in hanging-drop-cultures, and are figured and described by the author. The conditions for the development of the gelatinous sheaths-and therefore of the coherent brain-like masses of the Schizomycete-are a saccharine acid medium and absence of oxygen. The process occurs best in carbon dioxide : it is suppressed in bouillon, and in neutra solutions in hydrogen, though the organism grows in the free, non-sheathed, motile form under these conditions.

The behaviour of pure cultures of the bacteria in as complete a vacuum as could be produced by a good mercury pump, worked daily, and even several times a day, for several weeks, is also noteworthy. The development of the sheaths is apparently in definitely postponed in vacuo, but the organism increased, and each time the pump was set going an appreciable quantity of carbon dioxide was obtained. In vacuum tubes the same gas was evolved, and eventually attained a pressure sufficient to burst some of the tubes. The quantity of carbon dioxide evolved daily by the action of the bacterium alone, however, is small compared with that disengaged when the organism is working in concert with the symbiotic yeast; in the latter case the pressure of the gas became so dangerous that the author had to abandon the use of sealed tubes.

The products of the fermentation due to the Schizomycete have not yet been fully determined in detail ; lactic acid, or some allied compound, seems to be the chief result, but there are probably other bodies as well. The author considers that the bacterium removes from the sphere of action substances which, if accumulated, would exhibit the fermentative power of the yeast, hence the advantages of the symbiosis.

The pink yeast-like form proved to be very interesting. It has nothing to do with the "ginger-beer plant" proper, though it was invariably met with as a foreign intruder in the specimens. The author identifies it with a form described by Hansen in 1879 ("Organismer i Öl og Ölurt," Copenhagen, 1879) unfortunately the original is in Danish, but the figures are so good that little doubt is entertained as to the identity. It is also probably the same as Fresenius's Cryptococcus glutinis in one of its forms. It is not a Saccharomycete, and does not ferment like a yeast; it is aërobian. 